\title{
Marriage is a dependent risk factor for mortality of colon adenocarcinoma without a time-varying effect
}

\author{
Minling Liu ${ }^{1,}{ }^{*}$, Lixian Li ${ }^{2,}{ }^{*}$, Wei Yu ${ }^{1}$, Jie Chen ${ }^{3}$, Weibin Xiong ${ }^{1}$, Shuang Chen ${ }^{1}$, Li Yu ${ }^{1}$ \\ ${ }^{1}$ Department of Pathology, Zhujiang Hospital, Southern Medical University, Guangzhou, China \\ ${ }^{2}$ Department of Biostatistics, School of Public Health, Southern Medical University, Guangzhou, China \\ ${ }^{3}$ Department of Oncology, Zhujiang Hospital, Southern Medical University, Guangzhou, China \\ *These authors have contributed equally to this work \\ Correspondence to: Li Yu, email: yuli60@163.com \\ Keywords: marriage, colon adenocarcinoma, time-varying effect, all-cause mortality, surveilance \\ Received: November 14, $2016 \quad$ Accepted: January 11,2017 Published: February 16, 2017
}

\section{ABSTRACT}

Background: It has been well recognized that the effects of many prognostic factors could change during long-term follow-up. Although marriage has been proven to be a significant prognostic factor for the survival of colon cancer, whether the effect of marriage is constant with time remain unknown. This study analyzed the impact of marital status on the mortality of colon cancer patients with an extended Cox model that allowed for time-varying effects.

Methods: We identified 71,955 patients who underwent colectomy between 2004 and 2009 to treat colon adenocarcinoma from the Surveilance, Epidemiology and End Results Database. The multivariate extended Cox model was used to evaluate the effect of marital status on all-cause mortality, while the Fine-Gray competing risks model was used for colon cancer-specific mortality, with death from other causes as the competing risk.

Results: The unmarried patients carried a 1.37-fold increased risk of all-cause mortality compared with the married patients (95\%CI: $1.33-1.40 ; \mathrm{p}<0.001)$, and the hazard ratio remained constant over time. Being unmarried was at a higher risk of death from colon adenocarcinoma as well as death from other causes. Four variables including tumor site, tumor grade, sex and TNM stage were proved to have timevarying effects on survival.

Conclusions: Marriage is a dependent prognosis factor for survival of surgically treated colon adenocarcinoma patients. Psychological interventions are suggested to improve receipt of treatment among unmarried patients, as their poor survival may be due to the inefficient treatment.

\section{INTRODUCTION}

Colorectal cancer is the third most common cancer in men worldwide $(746,000$ cases, $10.0 \%$ of the total) and the second most common cancer in women $(614,000$ cases, $9.2 \%$ of the total) [1]. In addition, colorectal cancer is the fourth leading cause of cancer-related deaths, with 693,000 deaths worldwide per year [1]. The survival of this type of cancer is affected by many factors, such as age, grade, stage, tumor site [2], molecular pathogenesis, treatment regimen and socioeconomic status. Marriage, as an important psychosocial factor, has been proven to be a significant prognostic factor for many cancers [3-14]. Previous studies using the Cox proportional hazards regression model (Cox PH model) have demonstrated that being married at the time of diagnosis is associated with a better survival of colorectal cancer [6, 11-14]. These conclusions could be misleading if marital status has a time-varying effect, because the Cox $\mathrm{PH}$ model relies on a fundamental proportional hazard (PH) assumption, which is that the relative risks of the covariates do not change over time. However, whether marriage has a time-varying effect on the survival of colorectal cancer patients remains unknown. To investigate this question, we performed this 
study based on data from the Surveilance, Epidemiology and End Results [15] (SEER) database, with an extended Cox model that allowed for time-varying effects. We tried to make the cohort more comparable by limiting patients who underwent colectomy for colon adenocarcinoma.

\section{RESULTS}

\section{Patient characteristics}

Of the 71,955 patients included in our analyses, 41,126 patients $(57.16 \%)$ were married and 30,829 (42.84\%) were unmarried. There were 16,298(39.63\%) deaths in married group, including 11,005 died of colon cancer and 5,293 died due to other reasons. There were $16,232(52.65 \%)$ deaths in unmarried group, including 9,749 died for colon cancer and 6,483 died due to other reasons. The clinical and demographic characteristics of the study cohort according to marital status are summarized in Table 1. In general, unmarried patients were, on average, 4.85 years older than married patients and were significantly more likely to be both female and black, have right-side cancer, have higher grade tumors, be at an advanced tumor stage, but be at an earlier AJCC stage $(\mathrm{p}<0.001)$. The proportion of patients who presented with metastatic disease was similar between the married and unmarried group (15.0\% VS $14.8 \%, \mathrm{p}=0.776)$, which is inconsistent with previous studies [12, 13]. There was no significant difference in lymph node metastasis between two groups.

\section{Impact of marital status on all-cause mortality}

The median OS of all the patients was 99 months, the median OS of the unmarried group was 70 months and that of the married group was not determined until the last follow-up time(log-rank $p<0.001$, Figure 1). The findings for all-cause mortality are presented in Table 2. In the univariate analysis, patients who were married at the date of diagnosis survived significantly longer than those who were unmarried (HR: 1.50; 95\% CI, 1.47-1.54; $\mathrm{p}<0.001)$. Other variables were also strongly correlated with all-cause mortality (all $\mathrm{p}<0.05$, Table 2 ). Performing a multivariate analysis, both the extended Cox model and Cox PH model showed that increasing age, being black, being male, being unmarried, having a right-side tumor, having a higher tumor grade, having a more advanced TNM stage and a higher LNR were significant adverse prognostic factors $(p<0.05$, Table 2$)$. In multivariate analysis with the extended Cox model, four variables including tumor site, tumor grade, sex and TNM stage showed time-varying effects on survival, while marriage did not. An unmarried status carried a 1.37-fold increase in the risk of death compared with a married status (95\%CI, 1.33-1.40; $<<0.001)$. Figure 2 displays the HR curve of each variable for all-cause mortality over time after adjustment for other variables. The HR curves of marriage, race, age and LNR for all-cause mortality remained relatively stable over time. The impact of tumor site and grade on all-cause mortality decreased over time, while that of sex and TNM stage increased over time.

\section{Impact of marital status on cancer-specific mortality}

The results from the multivariate Fine and Gray competing risks regression model are shown in Table 3. The CIF curves are plotted in Figure 3. The 5-year cancerspecific mortality rate was $24.76 \%$ for the married patients and $30.01 \%$ for the unmarried patients $(\mathrm{p}<0.001)$. Marital status was a significant independent predictor of colon cancer death, with an $20.7 \%$ increased risk of cancerspecific mortality for the unmarried patients compared with that for the married patients(HR,1.21; 95\%CI, 1.17$1.24 ; \mathrm{p}<0.001)$. The unmarried patients also had a greater probability of death from other causes (data not shown, Figure 4). An older age, being black, being male, having a right-side tumor, and a higher grade or TNM stage were associated with an increased risk of death from colon cancer (all $\mathrm{p}<0.001$ ), findings that were similar to the results of the all-cause mortality analysis.

\section{DISCUSSION}

Using the SEER database, we identified 71,955 patients who underwent colectomy for colon adenocarcinoma. Kaplan-Meier curves showed that the median OS of the unmarried group was significantly shorter than that of the married group (70months vs more than 120months). When we performed a multivariate analysis with an extended Cox model, we found that the unmarried patients carried a 1.37-fold increased risk of allcause deaths compared with the married patients, and this risk remained constant over time. Further analysis showed that being unmarried was at a higher risk of death from colon adenocarcinoma as well as death from other causes.

Why the married status result in more favorable OS is not totally clear yet. A recent research has observed that the survival benefits of marriage may not because of better material resources, including health insurance status and neighborhood socioeconomic status [16]. The lower colorectal cancer screening rate $[17][18,19]$, the higher metastatic cancer rate [12] [13] and the lower surgery rate [13]in unmarried group may be some potential reasons, because the early detection and early treatment can reduce mortality of cancer. But why the marriage continues to play a role even after surgery? In our opinion, it may be due to the inefficient treatment. For patients with surgically treated stage III colon cancer, the initiation and completion of adjuvant chemotherapy was largely influenced by marital status [20], and the chemotherapy use was lower in divorced and widowed patients [21]. 
Table 1: Baseline Characteristics of the study cohort according to Marital Status $(\mathrm{N}=71,955)$

\begin{tabular}{|c|c|c|c|}
\hline Characteristic & Married(n=41,126) & Unmarried(n=30,829) & $\mathbf{P}$ \\
\hline Vital status & & & $<0.001$ \\
\hline alive & $24,828(60.37 \%)$ & $14,597(47.35 \%)$ & \\
\hline dead for colon cancer & $11,005(26.76 \%)$ & $9,749(31.62 \%)$ & \\
\hline dead for other causes & $5,293(12.87 \%)$ & $6,483(21.03 \%)$ & \\
\hline Age & $65.64 \pm 12.8$ & $70.49 \pm 14.5$ & $<0.001$ \\
\hline Race & & & $<0.001$ \\
\hline white & $33,542(81.56 \%)$ & $23,805(77.22 \%)$ & \\
\hline Black & $3,625(8.81 \%)$ & $4,966(16.11 \%)$ & \\
\hline Other & $3,959(9.63 \%)$ & $2,058(6.68 \%)$ & \\
\hline Sex & & & $<0.001$ \\
\hline Male & $23,982(58.31 \%)$ & $10,485(34.01 \%)$ & \\
\hline female & $17,144(41.69 \%)$ & $20,344(65.99 \%)$ & \\
\hline Tumor site & & & $<0.001$ \\
\hline left & $17,034(41.42 \%)$ & $11,281(36.59 \%)$ & \\
\hline right & $23,516(57.18 \%)$ & $19,004(61.64 \%)$ & \\
\hline large intestine, NOS & $576(1.40 \%)$ & $544(1.76 \%)$ & \\
\hline Grade & & & $<0.001$ \\
\hline grade I & $3,911(9.51 \%)$ & $2,879(9.34 \%)$ & \\
\hline grade II & $29,190(70.98 \%)$ & $21,436(69.53 \%)$ & \\
\hline grade III & $7,441(18.09 \%)$ & $6,058(19.65 \%)$ & \\
\hline grade IV & $584(1.42 \%)$ & $456(1.48 \%)$ & \\
\hline Stage & & & $<0.001$ \\
\hline stage $0 / \mathrm{I}$ & $9,870(24.00 \%)$ & $6,432(20.86 \%)$ & \\
\hline stage II & $12,357(30.05 \%)$ & $10,353(33.58 \%)$ & \\
\hline stage III & $12,729(30.95 \%)$ & $9,470(30.72 \%)$ & \\
\hline stage IV & $6,170(15.00 \%)$ & $4,574(14.84 \%)$ & \\
\hline Tumor stage & & & $<0.001$ \\
\hline Tis/T0/Tx & $570(1.39 \%)$ & $363(1.18 \%)$ & \\
\hline $\mathrm{T} 1$ & $5,070(12.33 \%)$ & $2,947(9.56 \%)$ & \\
\hline $\mathrm{T} 2$ & $6,269(15.24 \%)$ & $4,364(14.16 \%)$ & \\
\hline $\mathrm{T} 3$ & $24,103(58.61 \%)$ & $18,774(60.90 \%)$ & \\
\hline $\mathrm{T} 4$ & $5,114(12.43 \%)$ & $4,381(14.21 \%)$ & \\
\hline Nodal stage & & & 0.102 \\
\hline N0 & $23,200(56.41 \%)$ & $17,637(57.21 \%)$ & \\
\hline N1 & $10,247(24.92 \%)$ & $7,611(24.69 \%)$ & \\
\hline $\mathrm{N} 2$ & $7,672(18.65 \%)$ & $5,573(18.08 \%)$ & \\
\hline $\mathrm{Nx}$ & $7(0.02 \%)$ & $8(0.03 \%)$ & \\
\hline Metastatic disease & & & 0.776 \\
\hline M0 & $34,953(85.00 \%)$ & $26,252(85.15 \%)$ & \\
\hline M1 & $6,170(15.0 \%)$ & $4,574(14.84 \%)$ & \\
\hline Mx & $3(0.01 \%)$ & $3(0.01 \%)$ & \\
\hline
\end{tabular}

(Continued) 


\begin{tabular}{lccc}
\hline Characteristic & Married(n=41,126) & Unmarried(n=30,829) & P \\
\hline Lymph node rates & & & 0.096 \\
$0.00 \leq \mathrm{LNR}<0.17$ & $30,521(74.21 \%)$ & $22,990(74.57 \%)$ & \\
$0.17 \leq \mathrm{LNR}<0.41$ & $5,668(13.78 \%)$ & $4,301(13.95 \%)$ & \\
$0.41 \leq \mathrm{LNR}<0.69$ & $2,839(6.90 \%)$ & $1,987(6.44 \%)$ & \\
$0.69 \leq \mathrm{LNR}$ & $2,098(5.10 \%)$ & $1,551(5.03 \%)$ & \\
\hline
\end{tabular}

Abbreviations: NOS, not otherwise specified; LNR, lymph node rates.

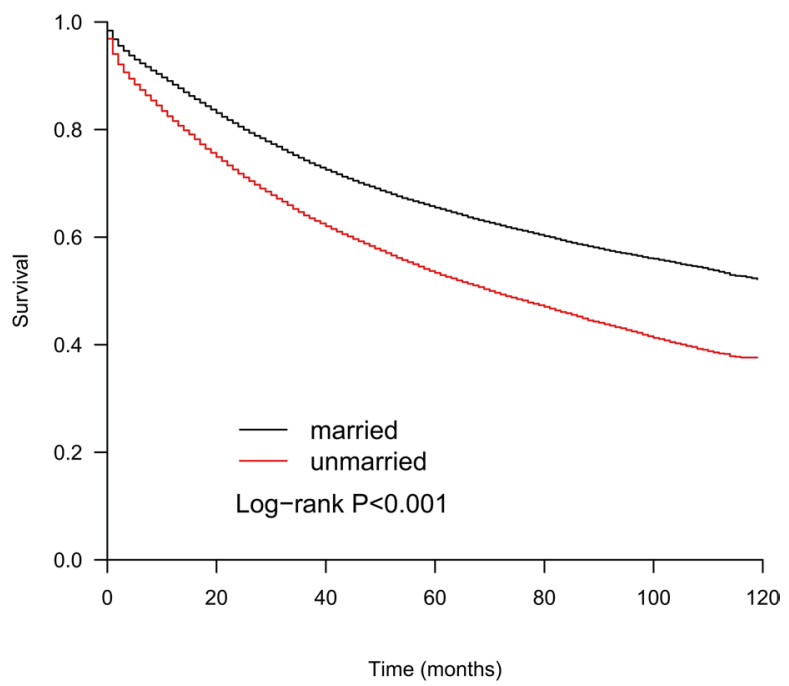

Figure 1: The Kaplan-Meier curves show that the OS of the married patients is better than that of the unmarried patients $(\mathbf{p}<0.001)$.
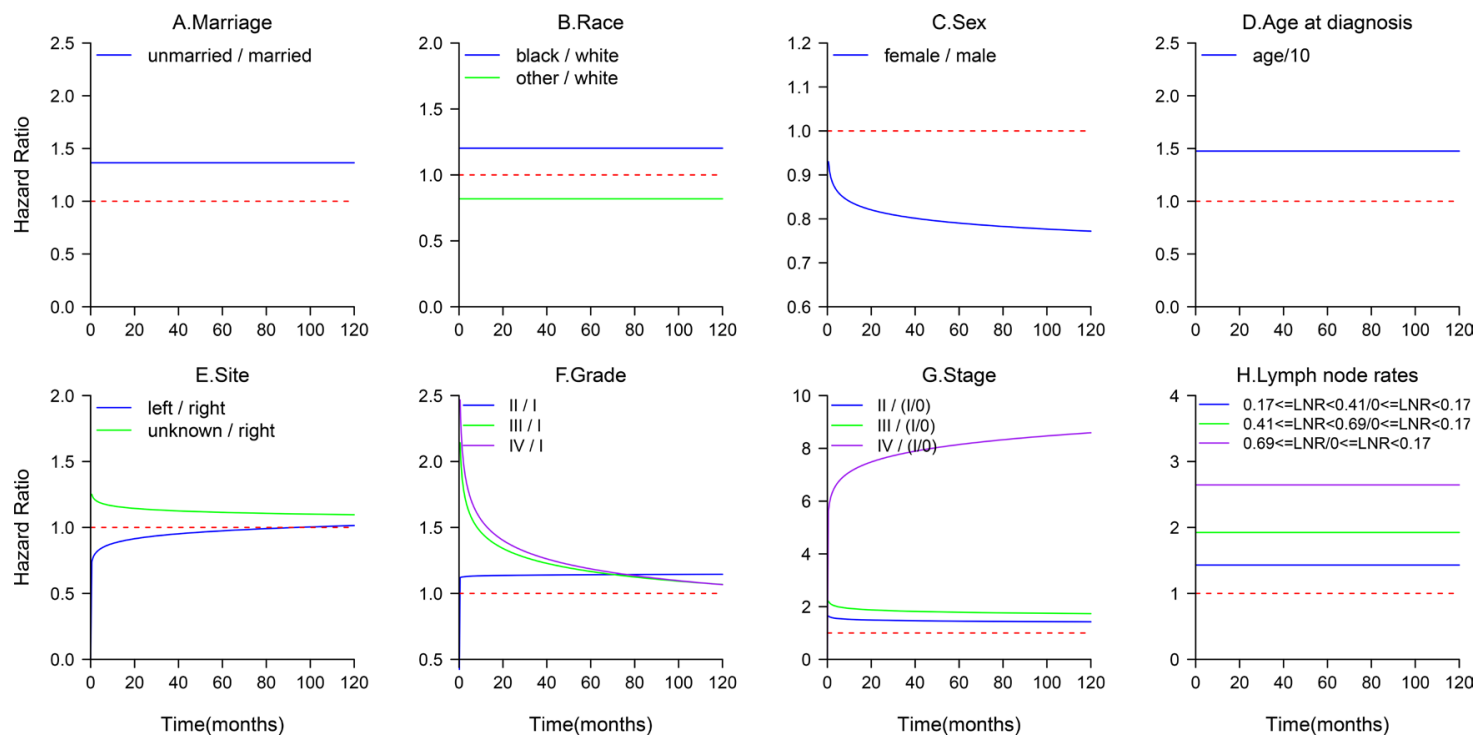

Figure 2: Time-varying effect of each factor on all-cause mortality. A. The HR of unmarried patients was relatively stable over time. D, B. The HR curve of age and race did not exhibit a clearly obvious change with time. C. Using females as a reference, the risk associated with the male gender increased over time. E. The impact of tumor site decreased over time. F. The HR of grade III or IV patients compared with that of grade I patients decreased rapidly within 2 years. G. The HR of stage IV patients compared with that of stage I patients increased with a longer survival time. H. The effects of LNR on all-cause mortality remained constant. 
Table 2: Univariate and Multivariate analysis for all-cause mortality

\begin{tabular}{|c|c|c|c|c|c|c|c|c|c|c|}
\hline \multirow{3}{*}{ Variable } & \multicolumn{6}{|c|}{ Cox Proportional Hazard Model } & \multirow{2}{*}{\multicolumn{4}{|c|}{$\begin{array}{l}\text { Extended Cox Model } \\
\text { Multivariate Analysis }\end{array}$}} \\
\hline & \multicolumn{3}{|c|}{ Univariate analysis } & \multicolumn{3}{|c|}{ Multivariate Analysis } & & & & \\
\hline & HR(95\%CI) & $\mathbf{p}^{\mathbf{a}}$ & PH test* & HR(95\%CI) & $\mathbf{p}^{\mathbf{b}}$ & $\begin{array}{c}\text { PH } \\
\text { test* }\end{array}$ & $\begin{array}{c}\text { Baseline } \\
\text { HR(95\%CI) }\end{array}$ & $\mathbf{P}$ & $\begin{array}{c}\text { Time-Varying } \\
\text { HR(95\%CI) }\end{array}$ & $\mathbf{P}$ \\
\hline age & $1.37(1.36-1.39)$ & $<0.001$ & 0.166 & $1.49(1.47-1.50)$ & $<0.001$ & 0.613 & $1.48(1.46-1.49)$ & $<0.001$ & & \\
\hline \multicolumn{11}{|l|}{ race } \\
\hline white & ref & & & & & & Ref & & & \\
\hline black & $1.12(1.08-1.15)$ & $<0.001$ & 0.213 & $1.19(1.15-1.23)$ & $<0.001$ & 0.802 & $1.20(1.16-1.24)$ & $<0.001$ & & \\
\hline other & $0.76(0.73-0.79)$ & $<0.001$ & 0.074 & $0.81(0.77-0.85)$ & $<0.001$ & 0.893 & $0.82(0.78-0.86)$ & $<0.001$ & & \\
\hline \multicolumn{11}{|l|}{$\operatorname{sex}$} \\
\hline male & ref & & & & & & Ref & & & \\
\hline female & $0.97(0.95-0.99)$ & 0.003 & 0.028 & $0.81(0.80-0.83)$ & $<0.001$ & 0.014 & $0.91(0.85-0.97)$ & 0.002 & $0.97(0.95-0.99)$ & 0.001 \\
\hline \multicolumn{11}{|l|}{ marriage } \\
\hline married & ref & & & & & & ref & & & \\
\hline unmarried & $1.50(1.47-1.54)$ & $<0.001$ & 0.005 & $1.38(1.34-1.41)$ & $<0.001$ & 0.245 & $1.37(1.33-1.40)$ & $<0.001$ & & \\
\hline \multicolumn{11}{|l|}{ site } \\
\hline right & ref & & & & & & ref & & & \\
\hline left & $0.84(0.82-0.86)$ & $<0.001$ & $<0.001$ & $0.93(0.91-0.95)$ & $<0.001$ & $<0.001$ & $0.77(0.72-0.82)$ & $<0.001$ & $1.06(1.04-1.08)$ & $<0.001$ \\
\hline unknown & $1.25(1.15-1.35)$ & $<0.001$ & 0.003 & $1.18(1.09-1.28)$ & $<0.001$ & 0.067 & $1.23(1.00-1.51)$ & 0.049 & $0.98(0.91-1.04)$ & 0.487 \\
\hline \multicolumn{11}{|l|}{ grade } \\
\hline I & ref & & & & & & ref & & & \\
\hline II & $1.42(1.36-1.49)$ & $<0.001$ & 0.198 & $1.11(1.06-1.16)$ & $<0.001$ & 0.136 & $1.12(0.98-1.29)$ & 0.098 & $1.00(0.96-1.05)$ & 0.857 \\
\hline III & $2.23(2.13-2.34)$ & $<0.001$ & $<0.001$ & $1.32(1.26-1.39)$ & $<0.001$ & $<0.001$ & $1.96(1.70-2.27)$ & $<0.001$ & $0.88(0.84-0.92)$ & $<0.001$ \\
\hline IV & $2.38(2.17-2.60)$ & $<0.001$ & $<0.001$ & $1.43(1.31-1.57)$ & $<0.001$ & 0.001 & $2.22(1.76-2.79)$ & $<0.001$ & $0.86(0.80-0.93)$ & $<0.001$ \\
\hline \multicolumn{11}{|l|}{ stage } \\
\hline $\mathrm{I} / 0$ & ref & & & & & & ref & & & \\
\hline II & $1.62(1.56-1.68)$ & $<0.001$ & $<0.001$ & $\begin{array}{c}1.49(1.44-1.55) \\
(1.44-1.55)\end{array}$ & $<0.001$ & $<0.001$ & $1.61(1.42-1.83)$ & $<0.001$ & $0.97(0.94-1.01)$ & 0.169 \\
\hline III & $2.32(2.24-2.41)$ & $<0.001$ & $<0.001$ & $\begin{array}{c}1.85(1.78-1.93) \\
(1.78-1.93)\end{array}$ & $<0.001$ & $<0.001$ & $2.14(1.89-2.42)$ & $<0.001$ & $0.96(0.92-0.99)$ & 0.015 \\
\hline IV & $8.29(7.99-8.61)$ & $<0.001$ & $<0.001$ & $6.86(6.57-7.16)$ & $<0.001$ & 0.031 & $5.94(5.26-6.71)$ & $<0.001$ & $1.08(1.04-1.12)$ & $<0.001$ \\
\hline \multicolumn{11}{|l|}{ LNR } \\
\hline $0.00 \leq \mathrm{LNR}<0.17$ & ref & & & & & & ref & & & \\
\hline $0.17 \leq \mathrm{LNR}<0.41$ & $2.11(2.05-2.17)$ & $<0.001$ & $<0.001$ & $1.41(1.36-1.46)$ & $<0.001$ & 0.168 & $1.43(1.38-1.48)$ & $<0.001$ & & \\
\hline $0.41 \leq \mathrm{LNR}<0.69$ & $3.12(3.01-3.23)$ & $<0.001$ & $<0.001$ & $1.90(1.82-1.97)$ & $<0.001$ & 0.798 & $1.92(1.85-2.01)$ & $<0.001$ & & \\
\hline $0.69 \leq \mathrm{LNR}$ & $5.23(5.04-5.43)$ & $<0.001$ & $<0.001$ & $2.59(2.48-2.71)$ & $<0.001$ & 0.046 & $2.64(2.53-2.77)$ & & & \\
\hline
\end{tabular}

Abbreviations: HR, hazard ratio; CI, confidence interval; LNR, lymph node rates.

* Grambsch - Therneau proportional hazards test

a: In univariate analysis, all variables were strongly correlated with all-cause mortality (all $\mathrm{p}<0.05)$

b:we conducted non-proportionality test in univariate analysis with Cox PH model, and we identify that sex, marriage, tumor site, tumor grade, tumor stage, lymph node rates were time-dependent factors $(\mathrm{p}<0.05)$. But when we conducted nonproportionality test in multivariate analysis with Cox PH model, we identify that marriage, lymph node rates satisfied the PH assumption $(\mathrm{p}>0.05)$.

$\mathrm{c}$ :A multivariate analysis with a time-dependent Cox model for all-cause mortality was performed using the following factors: age, race, sex $(* \log \mathrm{t})$, marriage, tumor $\operatorname{site}(* \log \mathrm{t})$, tumor grade $(* \log \mathrm{t})$, tumor stage $(* \log \mathrm{t}), \operatorname{lymph}$ node rates. 
Table 3: Fine and Gray Proportional Hazards Regression Analysis of colon cancer-specific mortality

\begin{tabular}{|c|c|c|}
\hline Variable/ Characteristic & HR(95\%CI) & $\mathbf{P}$ \\
\hline age & $1.18(1.17-1.20)$ & $<0.001$ \\
\hline \multicolumn{3}{|l|}{ race } \\
\hline white & ref & \\
\hline black & $1.21(1.16-1.26)$ & $<0.001$ \\
\hline other & $0.88(0.83-0.93)$ & $<0.001$ \\
\hline \multicolumn{3}{|l|}{$\operatorname{sex}$} \\
\hline male & ref & \\
\hline female & $0.92(0.90-0.95)$ & $<0.001$ \\
\hline \multicolumn{3}{|l|}{ marriage } \\
\hline married & ref & \\
\hline unmarried & $1.21(1.17-1.24)$ & $<0.001$ \\
\hline \multicolumn{3}{|l|}{ site } \\
\hline right & ref & \\
\hline left & $0.92(0.90-0.95)$ & $<0.001$ \\
\hline unknown & $1.14(1.02-1.27)$ & 0.016 \\
\hline \multicolumn{3}{|l|}{ grade } \\
\hline I & ref & \\
\hline II & $1.14(1.07-1.21)$ & $<0.001$ \\
\hline III & $1.44(1.35-1.54)$ & $<0.001$ \\
\hline IV & $1.41(1.25-1.60)$ & $<0.001$ \\
\hline \multicolumn{3}{|l|}{ stage } \\
\hline $\mathrm{I} / 0$ & ref & \\
\hline II & $2.86(2.65-3.07)$ & $<0.001$ \\
\hline III & $5.20(4.83-5.59)$ & $<0.001$ \\
\hline IV & $21.42(19.90-23.06)$ & $<0.001$ \\
\hline \multicolumn{3}{|l|}{ LNR } \\
\hline $0.00 \leq \mathrm{LNR}<0.17$ & ref & \\
\hline $0.17 \leq \mathrm{LNR}<0.41$ & $1.47(1.41-1.52)$ & $<0.001$ \\
\hline $0.41 \leq \mathrm{LNR}<0.69$ & $1.93(1.85-2.02)$ & $<0.001$ \\
\hline $0.69 \leq \mathrm{LNR}$ & $2.47(2.34-2.60)$ & $<0.001$ \\
\hline
\end{tabular}

Abbreviations: HR, hazard ratio; CI, confidence interval; LNR, lymph node rates.

Hazard ratios (95\% CIs) were derived from the competing risks model that was controlled for all variables mentioned in the above.

Besides, marital status have also been proven a significant variable associated with advancing through second- and subsequent-line treatments among metastatic colon cancer patients [22]. This issue needs to be looked at in future studies.

We recommend psychological supports for unmarried patients, as high levels of distress were found among unmarried colorectal cancer patients [23]. Although recent researches have failed to detect a survival benefit among patients who received psychological intervention [24-28], most of them did not further analyze unmarried patients. Those results could not be transferred straight forward. Whether unmarried patients will benefit from psychosocial intervention should be further explored.

It has been well recognized that prognostic effects could change during long-term follow-up. These 
prognostic factors include age [29-31], tumor stage [31], tumor grade [32-34], tumor size [30, 33, 35, 36], nodal status $[30,33,36]$, hormone receptor status $[32,34,35$, 37], gene mutations [38], tumor marker status [39], drug exposure and chemotherapy [30, 40, 41]. In this study, four variables including tumor site, tumor grade, sex and TNM stage were also proved to have time-varying effect on all cause mortality. The Cox PH model may lead to biased estimates for time-varying factors since it assume that the relative risks of the covariates do not change over time. Quantin C et al had compared Cox $\mathrm{PH}$ model and some non-proportional hazard survival models in modeling the impact of prognostic factors on all-cause mortality in colon cancer, found that the effects
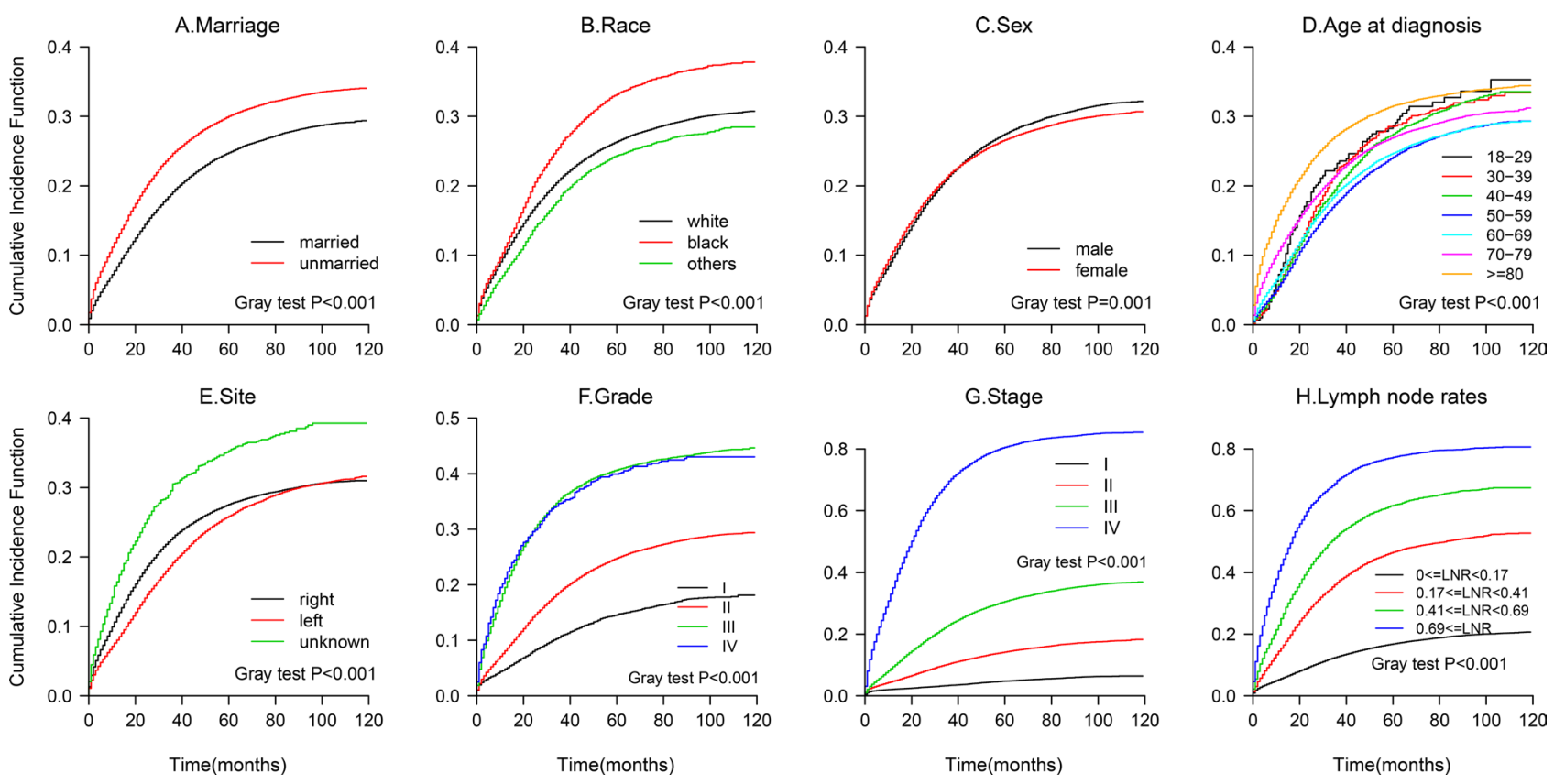

Figure 3: Cumulative Incidence Function (CIF) of deaths from colon adenocarcinoma.
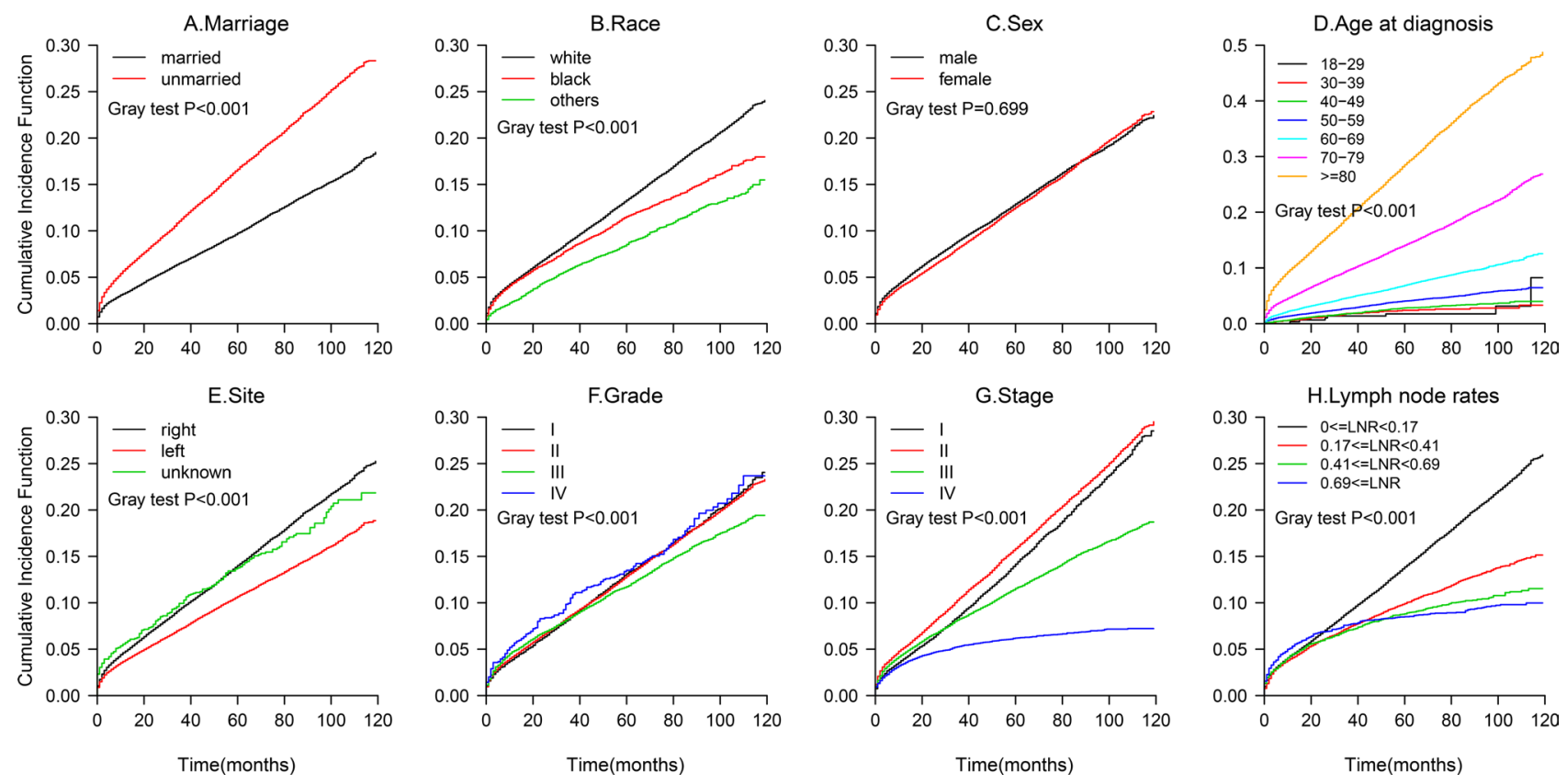

Figure 4: Cumulative Incidence Function (CIF) of deaths from other causes. 
of most clinical prognostic factors are non-proportional, illustrated that non-proportional survival models are more appropriate and better understanding the time-dependent aspect of prognostic factors [31].[42].

Due to the nature of these data, potential limitations of our study should be considered. First, we could not examine information about chemotherapy or other complementary treatments which could affect mortality. Second, the molecular markers of prognosis, such as microsatellite instability, immune cell infiltration, RAS and other gene mutations, were not presented in the database [43]. Third, changes in the marital status that occurred since the diagnosis are not available in this database. We were unable to account for those markers in our multivariate model.

Despite these potential limitations, we have found that unmarried patients were associated with a higher all-cause mortality risk, and this HR did not change over time. Being unmarried was at a higher risk of death from colon adenocarcinoma as well as death from other causes. Clinicians should assess marital status as a marker of prognosis of colon cancer. Our study points to the need for psychological interventions to improve receipt of treatment among unmarried patients.

\section{MATERIALS AND METHODS}

\section{Data source}

We collected data from the November 2015 submission of the SEER Database (http://www.seer. cancer.gov/) using the SEER*Stat software (Version 8.3.2). Sponsored by the National Cancer Institute, the SEER program includes cancer cases diagnosed from 1973 to 2013, collects data on patient demographics, tumor characteristics, limited treatment information, and survival information. It includes patients from 18 SEER registries, covers approximately 30 percent of the US population, and is an authoritative source of information on cancer incidence and survival in the US.

First, the initial cohort of 78,647 patients who underwent colectomy between 2004 and 2009 to treat colon adenocarcinoma was identified according to the following filter conditions. The patients with colon adenocarcinoma were identified using the International Classification of Diseases for Oncology, 3rd Edition (ICD-O-3/WHO 2008) site codes as "colon excluding rectum" and the ICD-O-3 morphology codes 8140-8141, $8143,8145,8147,8210-8211,8220-8221,8255,8260-$ $8263,8310,8323,8480-8481$, and 8570-8576, while the patients who underwent colectomy were enrolled using site-specific surgery codes $30,40,50,60,70$, and 80. The period was restricted from 2004 to 2009, during which cancers were classified based on the American Joint Committee on Cancer (AJCC) 6th edition staging criteria. We excluded patients with an unknown marital status, those with two or more malignant tumors, those who were alive or had died without a survival time, and those diagnosed by death certificate or autopsy only.

Of 78,647 patients, we further excluded patients who were less than 18 years of age $(\mathrm{N}=14)$, those lacking a histological grade $(\mathrm{N}=3,528)$, those whose stage was coded as "unknown" or "not applicable" $(\mathrm{N}=849)$, those without lymph a node examination, those cases in which the number of nodes examined or whether the nodes were examined was not known $(\mathrm{N}=2,042)$, those with an unknown number of positive lymph nodes or nodes that were not known to be positive or negative $(\mathrm{N}=33)$, and those with an unknown race or ethnicity $(\mathrm{N}=226)$, leaving 71,955 patients for the survival study.

\section{Variables of interest}

We obtained information routinely recorded at diagnosis for each patient, including age, sex (male vs female), marital status (married vs unmarried), race (white, black, other), tumor site, histological grade, $\mathrm{T}$ classification, $\mathrm{N}$ classification, $\mathrm{M}$ classification, and TNM stage (AJCC 6th), the total number of lymph nodes removed, the total number of positive lymph nodes, vital status, the underlying cause of death from the death certificate, and survival months. When we limited the cancer site to the colon, excluding the rectum, the following 9 sites were included in the SEER database: the appendix, cecum, ascending colon, hepatic flexure, transverse colon, splenic flexure, descending colon, sigmoid colon, and large intestine, (not otherwise specified). The tumor sites were divided into three groups, left-side tumors (splenic flexure to sigmoid descending colon), right-side tumors (appendix to transverse colon), and large intestine, NOS. Patients who were single, separated, divorced, or widowed at diagnosis were divided into the unmarried group, while patients who were married (including common law marriages) were divided into the married group. In the current study, we calculated a new variable, lymph node ratio (LNR), which was defined as the number of positive lymph nodes divided by the number of lymph nodes examined. LNR has been proven to be a strong independent prognostic factor for colon cancer [44-46], and the cut-off values of $0.17,0.41$ and 0.69 were recommended for the risk group stratification [44-46].

\section{Outcome of interest}

The follow-up time was calculated from the date of diagnosis to death or the date the study ended (December $31,2013)$. Deaths from any cause were used as primary events, while deaths from colon adenocarcinoma were considered as secondary events. We calculated the overall survival (OS) as the number of months from the date of diagnosis until death from any cause. All the patients who 
remained alive on December 31, 2013 were considered censored.

\section{Statistical analysis}

The baseline characteristics of the study cohort according to survival status were compared using a $\mathrm{t}$-test for continuous variables and a chi-squared test for categorical variables. Survival curves were constructed using the Kaplan-Meier method and were compared using the log-rank test for each factor in a univariate analysis. All factors were verified for the assumption of the Cox PH model using Therneau-Grambsch PH tests. A $\mathrm{p}$-value $<0.05$ indicated a violation of the $\mathrm{PH}$ assumption. As shown in Table 2, in the events of OS, some variables did not meet the assumption $(\mathrm{p}<0.05)$. Therefore, we further multivariate analysis on all-cause mortality using an extended Cox model (a simple extension with a time-varying coefficient model) [47]. T classification, $\mathrm{N}$ classification, and $\mathrm{M}$ classification were not included in the multivariate analysis due to the collinearities with TNM stage. The extended Cox model was adjusted for age, race, sex, marriage, tumor site, tumor grade, tumor stage, lymph node rates. For variables with time-varying effects, their hazard ratio (HR) at a given time(t) was calculated using the following formula: $\mathrm{HR}(\mathrm{t})=\mathrm{HR}_{\text {constant-effect }} \times\left(\mathrm{HR}_{\text {time-varying- }}\right.$ $\wedge \log (\mathrm{t}))$. The Fine-Gray competing risks model was utilized to determine cancer-specific mortality, with death from other causes as the competing risk. The probabilities of cancer-specific mortality and competing risk mortality were described using the cumulative incidence function (CIF), which was compared using Gray's test between the groups. Statistical analyses were performed using the $\mathrm{R}$ software (version 4.3.2). All the statistical tests were 2 -tailed and were performed at a p-value less than 0.05 .

\section{CONFLICTS OF INTEREST}

The authors declare that no potential conflicts of interest exist.

\section{FUNDING SUPPORT}

No specific funding was obtained.

\section{Author contributions}

Liu M was responsible for conceptualization, methodology, validation, investigation, resources, data curation, writing, visualization, and project administration. $\mathrm{Li} \mathrm{L}$ was responsible for methodology, software, formal analysis, and data curation. Yu W, Chen J, Xiong W, and Chen $\mathrm{S}$ had a contribution to investigation, resources, and writing an original draft. Yu L was responsible for supervision and funding acquisition. All authors reviewed and approved the manuscript.

\section{REFERENCES}

1. Ferlay J, Soerjomataram I, Ervik M, Dikshit R, Eser S, Mathers C, Rebelo M, Parkin DM, Forman D, Bray F. GLOBOCAN 2012 v1.0, Cancer Incidence and Mortality Worldwide: IARC CancerBase No. 112.

2. Schrag D, Weng S, Brooks G, Jeffrey A. The relationship between primary tumor sidedness and prognosis in colorectal cancer. J Clin Oncol 34, 2016.

3. He XK, Lin ZH, Qian Y, Xia D, Jin P, Sun LM. Marital status and survival in patients with primary liver cancer. Oncotarget. 2016 Aug 5. doi: 10.18632/oncotarget.11066. [Epub ahead of print].

4. Li J, Wang Y, Han F, Wang Z, Xu L, Tong J. Disadvantage of survival outcomes in widowed patients with colorectal neuroendocrine neoplasm: an analysis of surveillance, epidemiology and end results database. Oncotarget. 2016; 7:83200-83207. doi: 10.18632/oncotarget.13078.

5. Li M, Dai CY, Wang YN, Chen T, Wang L, Yang P, Xie D, Mao R, Chen C. Marital status is an independent prognostic factor for tracheal cancer patients: an analysis of the SEER database. Oncotarget. 2016; 7:77152-77162. doi: 10.18632/ oncotarget.12809.

6. Li Q, Gan L, Liang L, Li X, Cai S. The influence of marital status on stage at diagnosis and survival of patients with colorectal cancer. Oncotarget. 2015; 6:7339-7347. doi: 10.18632/oncotarget.3129.

7. Shi RL, Chen Q, Yang Z, Pan G, Zhang Z, Wang W, Liu S, Zhang D, Jiang D, Liu W. Marital status independently predicts gastric cancer survival after surgical resection--an analysis of the SEER database. Oncotarget. 2016; 7:1322813235. doi: 10.18632/oncotarget.7107.

8. Wang XD, Qian JJ, Bai DS, Li ZN, Jiang GQ, Yao J. Marital status independently predicts pancreatic cancer survival in patients treated with surgical resection: an analysis of the SEER database. Oncotarget. 2016; 7:24880-24887. doi: 10.18632/oncotarget.8467.

9. Wu C, Chen P, Qian JJ, Jin SJ, Yao J, Wang XD, Bai DS, Jiang GQ. Effect of marital status on the survival of patients with hepatocellular carcinoma treated with surgical resection: an analysis of 13,408 patients in the surveillance, epidemiology, and end results (SEER) database. Oncotarget. 2016; 7:79442-79452. doi: 10.18632/oncotarget.12722.

10. Zhang J, Gan L, Wu Z, Yan S, Liu X, Guo W. The influence of marital status on the stage at diagnosis, treatment, and survival of adult patients with gastric cancer: a populationbased study. Oncotarget. 2016 Feb 15. doi: 10.18632/ oncotarget.7399.

11. Johansen C, Schou G, Soll-Johanning H, Mellemgaard A, Lynge E. Influence of marital status on survival from colon and rectal cancer in Denmark. British journal of cancer. 1996; 74:985-988.

12. Wang L, Wilson SE, Stewart DB, Hollenbeak CS. Marital status and colon cancer outcomes in US Surveillance, 
Epidemiology and End Results registries: does marriage affect cancer survival by gender and stage? Cancer epidemiology. 2011; 35:417-422.

13. Aizer AA, Chen MH, McCarthy EP, Mendu ML, Koo S, Wilhite TJ, Graham PL, Choueiri TK, Hoffman KE, Martin NE, Hu JC, Nguyen PL. Marital status and survival in patients with cancer. Journal of clinical oncology. 2013; 31:3869-3876.

14. Villingshoj M, Ross L, Thomsen BL, Johansen C. Does marital status and altered contact with the social network predict colorectal cancer survival? European journal of cancer. 2006; 42:3022-3027.

15. Regs Research Data+ Hurricane Katrina Impacted Lousiana Cases. Nov 2015 Sub (1973-2013 varying). Available from URL: www.seer.cancer.gov. [accessed July 1, 2016].

16. Gomez SL, Hurley S, Canchola AJ, Keegan TH, Cheng I, Murphy JD, Clarke CA, Glaser SL, Martinez ME. Effects of marital status and economic resources on survival after cancer: A population-based study. Cancer. 2016; 122:1618-1625.

17. El-Haddad B, Dong F, Kallail KJ, Hines RB, Ablah E. Association of marital status and colorectal cancer screening participation in the USA. Colorectal disease. 2015; 17:O108-114.

18. Hanske J, Meyer CP, Sammon JD, Choueiri TK, Menon M, Lipsitz SR, Noldus J, Nguyen PL, Sun M, Trinh QD. The influence of marital status on the use of breast, cervical, and colorectal cancer screening. Preventive medicine. 2016; 89:140-145.

19. Wools A, Dapper EA, de Leeuw JR. Colorectal cancer screening participation: a systematic review. European journal of public health. 2016; 26:158-168.

20. Hu CY, Delclos GL, Chan W, Du XL. Assessing the initiation and completion of adjuvant chemotherapy in a large nationwide and population-based cohort of elderly patients with stage-III colon cancer. Medical oncology. 2011; 28:1062-1074.

21. Cress RD, Sabatino SA, Wu XC, Schymura MJ, Rycroft R, Stuckart E, Fulton J, Shen T. Adjuvant Chemotherapy for Patients with Stage III Colon Cancer: Results from a CDCNPCR Patterns of Care Study. Clinical medicine Oncology. 2009; 3:107-119.

22. Reese ES, Onukwugha E, Hanna N, Seal BS, Mullins CD. Clinical and demographic characteristics associated with the receipt of chemotherapy treatment among 7951 elderly metastatic colon cancer patients. Cancer medicine. 2013; 2:907-915.

23. Goldzweig G, Andritsch E, Hubert A, Walach N, Perry $\mathrm{S}$, Brenner B, Baider L. How relevant is marital status and gender variables in coping with colorectal cancer? A sample of middle-aged and older cancer survivors. Psychooncology. 2009; 18:866-874.

24. Gellert GA, Maxwell RM, Siegel BS. Survival of breast cancer patients receiving adjunctive psychosocial support therapy: a 10-year follow-up study. Journal of clinical oncology. 1993; 11:66-69.

25. Edelman S, Lemon J, Bell DR, Kidman AD. Effects of group CBT on the survival time of patients with metastatic breast cancer. Psycho-oncology. 1999; 8:474-481.

26. Goodwin PJ, Leszcz M, Ennis M, Koopmans J, Vincent L, Guther H, Drysdale E, Hundleby M, Chochinov HM, Navarro M, Speca M, Hunter J. The effect of group psychosocial support on survival in metastatic breast cancer. The New England journal of medicine. 2001; 345:1719-1726.

27. Ross L, Frederiksen K, Boesen SH, Karlsen RV, Rasmussen MS, Sorensen LT, Jorgensen T, Claesson MH, Johansen C. No effect on survival of home psychosocial intervention in a randomized study of Danish colorectal cancer patients. Psycho-oncology. 2009; 18:875-885.

28. Jassim GA, Whitford DL, Hickey A, Carter B. Psychological interventions for women with non-metastatic breast cancer. The Cochrane database of systematic reviews. 2015:Cd008729.

29. Jorgensen TL, Teiblum S, Paludan M, Poulsen LO, Jorgensen AY, Bruun KH, Hallas J, Herrstedt J. Significance of age and comorbidity on treatment modality, treatment adherence, and prognosis in elderly ovarian cancer patients. Gynecologic oncology. 2012; 127:367-374.

30. Tanis E, van de Velde CJ, Bartelink H, van de Vijver MJ, Putter H, van der Hage JA. Locoregional recurrence after breast-conserving therapy remains an independent prognostic factor even after an event free interval of 10 years in early stage breast cancer. European journal of cancer. 2012; 48:1751-1756.

31. Bolard P, Quantin C, Esteve J, Faivre J, Abrahamowicz M. Modelling time-dependent hazard ratios in relative survival: application to colon cancer. Journal of clinical epidemiology. 2001; 54:986-996.

32. Baulies S, Belin L, Mallon P, Senechal C, Pierga JY, Cottu P, Sablin MP, Sastre X, Asselain B, Rouzier R, Reyal F. Time-varying effect and long-term survival analysis in breast cancer patients treated with neoadjuvant chemotherapy. British journal of cancer. 2015; 113:30-36.

33. Warwick J, Tabar L, Vitak B, Duffy SW. Time-dependent effects on survival in breast carcinoma: results of 20 years of follow-up from the Swedish Two-County Study. Cancer. 2004; 100:1331-1336.

34. Bellera CA, MacGrogan G, Debled M, de Lara CT, Brouste $\mathrm{V}$, Mathoulin-Pelissier S. Variables with time-varying effects and the Cox model: some statistical concepts illustrated with a prognostic factor study in breast cancer. BMC medical research methodology. 2010; 10:1-20.

35. Sauerbrei W, Royston P, Look M. A new proposal for multivariable modelling of time-varying effects in survival data based on fractional polynomial time-transformation. Biometrical journal Biometrische Zeitschrift. 2007; 49:453-473. 
36. Verlato G, Marrelli D, Accordini S, Bencivenga M, Di Leo A, Marchet A, Petrioli R, Zoppini G, Muggeo M, Roviello F, de Manzoni G. Short-term and long-term risk factors in gastric cancer. World journal of gastroenterology. 2015; 21:6434-6443.

37. Dawson SJ, Makretsov N, Blows FM, Driver KE, Provenzano E, Le Quesne J, Baglietto L, Severi G, Giles GG, McLean CA, Callagy G, Green AR, Ellis I, et al. BCL2 in breast cancer: a favourable prognostic marker across molecular subtypes and independent of adjuvant therapy received. British journal of cancer. 2010; 103:668-675.

38. Candido-dos-Reis FJ, Song H, Goode EL, Cunningham JM, Fridley BL, Larson MC, Alsop K, Dicks E, Harrington P, Ramus SJ, de Fazio A, Mitchell G, Fereday S, et al. Germline mutation in BRCA1 or BRCA2 and ten-year survival for women diagnosed with epithelial ovarian cancer. Clinical cancer research. 2015; 21:652-657.

39. Chang C, Chiang AJ, Wang HC, Chen WA, Chen J. Evaluation of the Time-Varying Effect of Prognostic Factors on Survival in Ovarian Cancer. Annals of surgical oncology. 2015; 22:3976-3980.

40. Cormier JN, Huang X, Xing Y, Thall PF, Wang X, Benjamin RS, Pollock RE, Antonescu CR, Maki RG, Brennan MF, Pisters PW. Cohort analysis of patients with localized, highrisk, extremity soft tissue sarcoma treated at two cancer centers: chemotherapy-associated outcomes. Journal of clinical oncology. 2004; 22:4567-4574.

41. Margel D, Urbach DR, Lipscombe LL, Bell CM, Kulkarni G, Austin PC, Fleshner N. Metformin use and all-cause and prostate cancer-specific mortality among men with diabetes. Journal of clinical oncology. 2013; 31:3069-3075.
42. Quantin C, Abrahamowicz M, Moreau T, Bartlett G, MacKenzie T, Tazi MA, Lalonde L, Faivre J. Variation over time of the effects of prognostic factors in a populationbased study of colon cancer: comparison of statistical models. American journal of epidemiology. 1999; 150:1188-1200.

43. Brenner H, Kloor M, Pox CP. Colorectal cancer. Lancet. 2014; 383:1490-1502.

44. Berger AC, Sigurdson ER, LeVoyer T, Hanlon A, Mayer RJ, Macdonald JS, Catalano PJ, Haller DG. Colon cancer survival is associated with decreasing ratio of metastatic to examined lymph nodes. Journal of clinical oncology. 2005; 23:8706-8712.

45. Rosenberg R, Engel J, Bruns C, Heitland W, Hermes N, Jauch KW, Kopp R, Putterich E, Ruppert R, Schuster T, Friess H, Holzel D. The prognostic value of lymph node ratio in a population-based collective of colorectal cancer patients. Annals of surgery. 2010; 251:1070-1078.

46. Rosenberg R, Friederichs J, Schuster T, Gertler R, Maak M, Becker K, Grebner A, Ulm K, Hofler H, Nekarda H, Siewert JR. Prognosis of patients with colorectal cancer is associated with lymph node ratio: a single-center analysis of 3,026 patients over a 25-year time period. Annals of surgery. 2008; 248:968-978.

47. L T, Reyes EM. Tutorial: Survival Estimation for Cox Regression Models with Time-Varying Coefficients Using SAS and R. J Stat Softw. 2014; 61:1-23. 